\title{
Application of SS-VF Bed for the Treatment of High Concentrated Reject Water from Autothermal Termophilic Aerobic Sewage Sludge Digestion
}

\author{
Wojciech Dąbrowski ${ }^{1 *}$, Paweł Malinowski', Beata Karolinczak² \\ 1 Bialystok University of Technology, Faculty of Building and Environmental Engineering, Wiejska 45E, \\ 15-351 Białystok, Poland \\ 2 Warsaw University of Technology, Faculty of Building Service, Hydro and Environmental Engineering, \\ Nowowiejska 20, 00-653 Warsaw, Poland \\ * Corresponding author's e-mail: dabrow@pb.edu.pl
}

\begin{abstract}
The autothermal termophilic aerobic digestion (ATAD) technology is used in the municipal and industrial wastewater treatment plants (WWTPs) with personal equivalent up to 30.000. The process provides a high level of sewage sludge stabilization and its hygienization. The main operation problems are caused by the high concentration of nitrogen and phosphorus in the reject water from sewage sludge treatment and air purification (odor removal). Reject water usually is returned to the main sewage treatment, which has a negative impact, especially on the sewage treatment systems based on the sequence batch reactors (SBR). Applying high-performance and expensive separate reject water treatment methods such as SHARON, Anammox or CANON in small facilities is not justified economically. The article presents the research results concerning the effectiveness of applying subsurface vertical flow constructed wetlands (SS VF) for reject water treatment from the ATAD process. An innovative type of bed filling was used, which was produced from waste (ash from a heat and power plant). The efficiency of reject water treatment during the research period was on average at $45.6 \%$ for ammonia nitrogen, $32.3 \%$ for total phosphorus and $85.1 \%$ for $\mathrm{BOD}_{5}$. Applying SS VF beds for separate reject water treatment might ensure a stable and effective functioning of municipal WWTPs by decreasing the load of biological part of a WWTP.
\end{abstract}

Keywords: autothermal thermophilic aerobic digestion (ATAD), reject water, vertical flow constructed wetland (SS VF)

\section{INTRODUCTION}

The main tendencies in the development of municipal and industrial wastewater treatment plants (WWTPs) are connected with sewage sludge management. It is caused by the necessity of decreasing the content of organic substance, eliminating pathogenic microorganisms and limiting the volume and mass of sludge. Applying new technologies for treating the sludge from wastewater treatment plants (WWTPs) is commonly related to the problem of reject water, which is generated during thickening and final dewatering of sewage sludge.
Returning the reject water to the main sewage treatment line is a common solution. In the facilities applying aerobic digestion, the reject water does not cause any major exploitation problems; however, in large facilities with anaerobic digestion, its impact is substantial [Janus and Van der Roast 1997, Gajewska \& Obarska-Pempkowiak 2013, Dąbrowski et al. 2017].

Nowadays, the sewage sludge stabilization technology which involves the process of autothermal termophilic aerobic sewage sludge digestion (ATAD) is more popular in Poland [Bartkowska 2017]. The process can be applied both in the municipal and industrial WWTPs with per- 
sonal equivalent (PE) up to 30.000 or flow capacity is up to $20.000 \mathrm{~m}^{3} /$ day [Bartkowska \& Dzienis 2007, Bartkowska 2016]. In these WWTPs, using the anaerobic sewage sludge stabilization which allows for biogas and finally electric and heat energy production is not justified economically. The most essential advantages of the process are a very high level of sewage sludge stabilization and its hygienization, which can be safely recycled to the natural environment and used, for instance, as fertilizer [Layden et al. 2007, Schugen et al. 2011]. Among the issues connected with exploitation, there is a high concentration of biogenic compounds in the reject water produced during the sewage sludge dewatering and additionally from the air treatment carried out by means of a scrubber. The composition of reject water in a WWTP applying the ATAD process is similar to the objects utilizing sewage sludge under anaerobic conditions (digestion) [Dąbrowski 2014].

The reject water from ATAD process might have an exceptionally negative impact on the sewage treatment systems based on sequence batch reactors (SBR), especially when there is no retention and averaging tank. It is possible to apply separate reject water treatment. The most commonly known process is called Single Reactor System for High-Rate Ammonia Removal Over Nitrite (SHARON) [van Kempen et al. 2001]. This method, although highly effective, is nevertheless connected with high investment and exploitation costs. Alternatively, a low-cost constructed wetlands method can be used. It is currently applied for treating not only household or municipal wastewater, but also septage as well as various types of industrial sewage and reject water with high concentration of pollutants [Carvalho et al. 2017, Karolinczak \& Dąbrowski 2017, Liang et al. 2017, Tan et al. 2017].

The research explores the possibility of separate high efficiency treatment of the reject water generated during the ATAD process with subsurface vertical flow constructed wetland (SS-VF) filled with innovative lightweight sintered aggregate Certyd. The research focuses on decreasing the concentration of nitrogen and phosphorus, as well as organic substances. According to Science Direct, no studies on ATAD reject water treatment in constructed wetlands have been carried out thus far (date of search: $15^{\text {th }}$ January 2017, keywords: ATAD, reject water, constructed wetlands). Due to the lack of experiments concerning that process, the necessity for conducting the research with such goals was confirmed. The obtained results can be applied by the engineers designing full scale installations.

\section{MATERIALS AND METHODS}

\section{Characteristic of municipal WWTP}

The municipal WWTP in Wysokie Mazowieckie has been operating since 2016, the project flow equals $1344 \mathrm{~m}^{3} \mathrm{~d}^{-1}$ and $\mathrm{PE}-11200$. The sewage flow in 2017 varied from 1100 to 1500 $\mathrm{m}^{3} \mathrm{day}^{-1}, \mathrm{BOD}_{5}$ in raw sewage changed from 140 to $990 \mathrm{mg} \mathrm{O}_{2} \mathrm{l}^{-1}$.

It is a typical plant with mechanical, biological and chemical treatment. The screen and grid chamber prepare sewage for the biological treatment in two sequencing batch reactors (SBRs) aerated with Biogest Hyper Classic mixers and decanters. There is no averaging tank applied in the sewage line. The chemical precipitation of phosphorus occurs simultaneously with the treatment process. The excess sewage sludge is treated with the ATAD process. Two chambers are supplied with sludge after thickening with centrifuge; the final dewatering is realized with a filter press. Stabilization occurs in two sequential reactors. The sewage sludge from the first ATAD chamber is sent to the second chamber in portions using a sludge transfer pump after removing the portion of stabilized sludge from the second reactor. The temperature in the second reactor is over $56^{\circ} \mathrm{C}$ and the retention time is around 6 days. Figure 1 presents a general view of the municipal WWTP in Wysokie Mazowieckie with a scheme of sewage sludge treatment. Finally, sewage sludge is used as fertilizer. Due to the nuisance caused by the odor released from ATAD reactors (mainly high concentration of ammonia nitrogen), preliminary air treatment is necessary before it can be discharged into the atmosphere. The main elements of air purification installation are flow scrubber and NEUTRALOX device. Photoionization is an effective odor treatment process applied for all odors coming from the sewage and sludge treatment. The process is based on the effective interaction between UV-light and a catalytic converter.

The problem with a high concentration of nutrients in the reject water was observed in the WWTPs applying the ATAD process. The reject water (sewage sludge dewatering, thickening 

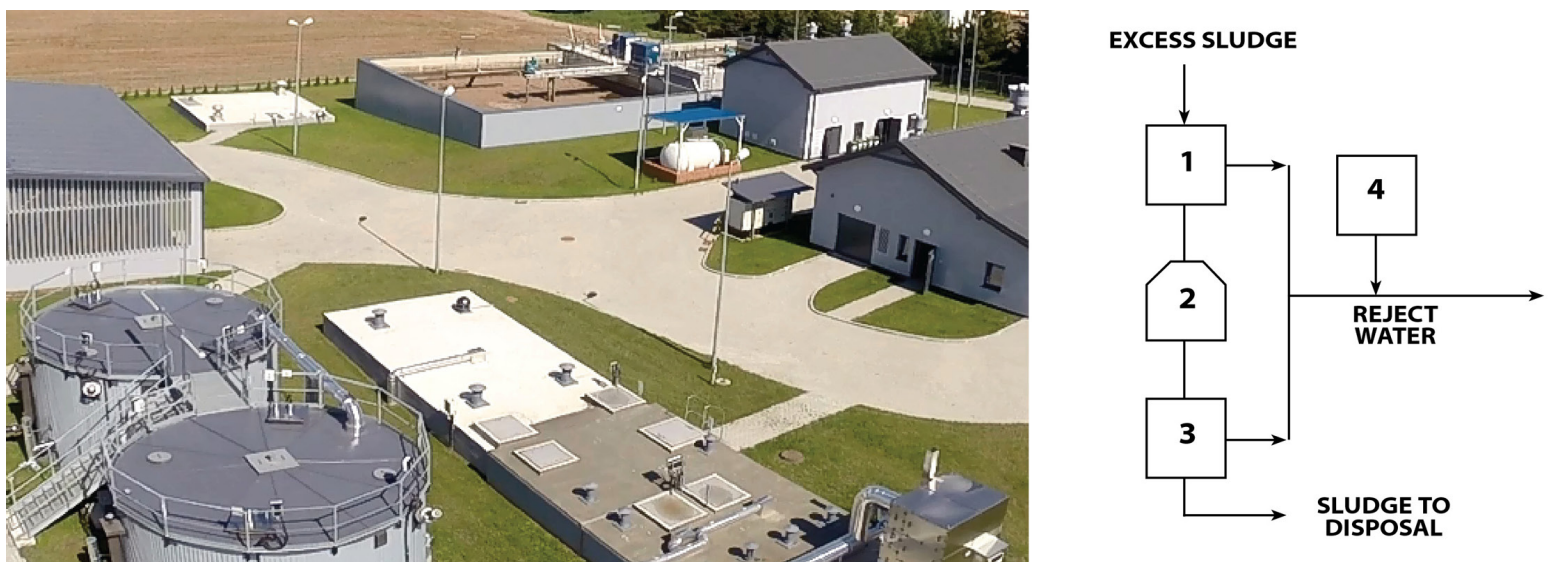

Fig. 1. A general view of municipal WWTP in Wysokie Mazowieckie with a scheme of sewage sludge treatment (1-centrifuge for thickening, 2-ATAD chambers, 3-filterpress for dewatering, 4-scroober)

[Dąbrowski and Zdziarski]

and scroober) is returned to the main sewage line without any separate treatment. The concentration of ammonia nitrogen and phosphorus in the reject water is similar as in the WWTPs applying anaerobic sewage sludge stabilization [Dąbrowski et al. 2017]. Taking into consideration the amount of generated reject water and its content, it should undergo primary treatment to remove the nitrogen compounds, phosphorus and organic matter before it enters the main technological line in a WWTP [Gui et al. 2009].

\section{Research installation}

The research installation based on the constructed wetlands technology was designed by the authors using the earlier experience with reject water treatment in dairy and municipal WWTPs [Kadlec \& Wallace 2009, Karolinczak \& Dąbrowski 2017, Dąbrowski et al. 2107]. The main element is a SS-VF bed with the height of $0.8 \mathrm{~m}$. In addition, the installation includes a retention tank, outflow and control wells. Figure 2 depicts the research installation in the summer 2017 and microscopic view of bed filling called Certyd.

In the SS-VF research installation, passive aeration systems were applied. The bed was built with innovative filling - Certyd. Lightweight sintered aggregate (LSA) Certyd is a ceramic and porous material. It is produced in accordance with the LSA technology featuring an innovative sintering process in a rotary furnace. It is obtained
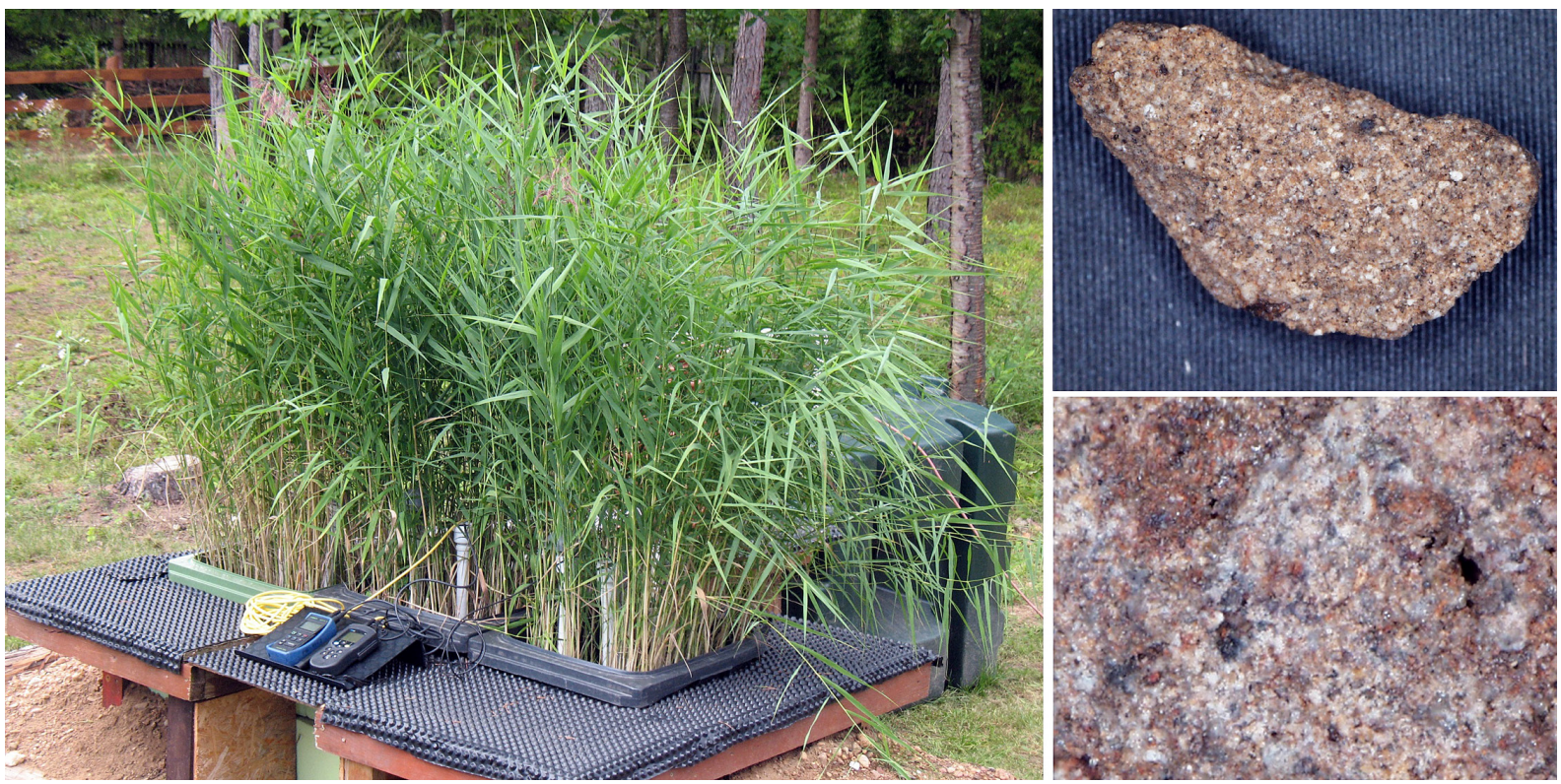

Fig. 2. ATAD reject water treatment installation and microscopic view of Certyd [Dąbrowski and Wasilewska] 
by a thermal processing of ash. The product conforms to the EN-13055:2016-07 standard as a lightweight aggregate. It has the declaration of National Institute of Hygiene no. HR/B/86/2015 [LSA LLC]. The bed is filled with three layers of Certyd characterized by varying granulation (2-9 $\mathrm{mm})$. The beds were planted with specially prepared reed (Phragmites australis) obtained from the Zambrów municipal WWTP.

\section{Sampling and scope of the determination}

The study was carried out from August to September 2017. The SS-VF bed was supplied from the retention tank. The daily hydraulic load was $0.1 \mathrm{~m}^{3} \mathrm{~m}^{-2}$. The samples were collected in 12 research series (influent to SS-VF and effluent). The air temperature during the experiment varied from $8^{\circ}$ to $12^{\circ} \mathrm{C}$. The basic physical and chemical analyses were performed: biochemical oxygen demand $\mathrm{BOD}_{5}$, chemical oxygen demand $\mathrm{COD}$, total organic carbon $\mathrm{TOC}$, total Kjeldahl nitrogen TKN, ammonia nitrogen $\mathrm{N}^{-\mathrm{NH}_{4}}{ }^{+}$, nitrate nitrogen (V) $\mathrm{N}_{-} \mathrm{NO}_{3}^{-}$, nitrite nitrogen (III) $\mathrm{N}-\mathrm{NO}_{2}^{-}$and total phosphorus TP. Unit loads in influent and effluent were used to calculate the removed load. Determinations were conducted in a certified laboratory, in accordance with the procedures set out in the Regulation of the Environmental Protection Minister from $18^{\text {th }}$ November 2014 and in line with the American Public Health Association (2005). Box and whiskers plots have been used as a graphical interpretation of the statistical analysis of influent, effluent and removed loads.

\section{RESULTS AND DISCUSSION}

Table 1 presents the basic operation parameters of the WWTP in 2017, concerning the actual quantity of sewage sludge and reject water generated during the sludge treatment.

Table 1. Basic parameters of the municipal WWTP in Wysokie Mazowieckie in 2017

\begin{tabular}{|l|c|c|}
\hline \multicolumn{1}{|c|}{ Parameter } & Unit & Value \\
\hline Sewage flow & $\mathrm{m}^{3} \mathrm{~d}^{-1}$ & 1300 \\
\hline P.E of sewage & - & 9035 \\
Sewage sludge quantity & tons of dry mass & 80.1 \\
& year $^{-1}$ & \\
\hline Reject water flow & $\mathrm{m}^{3} \mathrm{~d}^{-1}$ & 120 \\
P.E. of reject water & - & 660 \\
\hline
\end{tabular}

The amount of reject water in the analyzed WWTP utilizing ATAD was $9 \%$ of the total amount of raw sewage. According to the research by Ryzińska [2006], in 40 municipal WWTPs with anaerobic stabilization, the quantity of the reject water was ranged from 2.7 to $7 \%$. According to Janus \& van der Roest [1997], the quantity of reject water in Dutch WWTPs was below $2 \%$. Thus, it can be concluded that applying ATAD is connected with the generation of greater quantity of reject water in comparison with the plants applying common stabilization methods (aerobic or digestion).

Figure 3 compares the pollutants load in raw sewage and the reject water generated in ATAD process in WWTP.

The load of pollutants contained within the reject water depends on many factors, among which the most important are the type of treated sewage and stabilization methods. The analysis of the loads in WWTP with ATAD shows that in the case of organic and some non-organic compounds indicators, expressed as $\mathrm{BOD}_{5}$ and $\mathrm{COD}$, a higher load of pollutants is present in the sewage than in the reject water. The TN and TP loads are similar in the sewage and reject water from the ATAD process. However, the ammonia nitrogen load in this reject water exceeds its load in the municipal sewage. In the municipal WWTPs applying the typical stabilization processes, the load of total nitrogen in the reject water does not exceed $25 \%$ of its load in raw sewage [Janus \& van der Roest 1997, Meyer \& Wilderer 2004, Fux et al. 2006]. According to Ryzińska [2006] and Rosenwinkel et al.[2009], the share of biogenic compounds load might consitute from 10 to $30 \%$ of load in raw sewage, whereas the share of ammonia nitrogen varied from 1 to $50 \%$. The treatment systems for the reject water from the ATAD process ought to be designed with great consideration for the ammonia nitrogen load. Table 2 presents the characteristics of reject water from ATAD process before and after treatment with SS VF bed during the research period and removed pollutants load.

Comparing the achieved results of the research on the reject water from the ATAD process with the results present in literature, it can be observed that the nitrogen and phosphorus compounds have similar concentrations. According to Borowski [2000], the average concentration of ammonia nitrogen in the reject water from the ATAD process varied from 290 to $715 \mathrm{mg} \mathrm{N} \mathrm{1}^{-1}$, total nitrogen from 975 to $1569 \mathrm{mg} \mathrm{N}^{-1}$, and total 


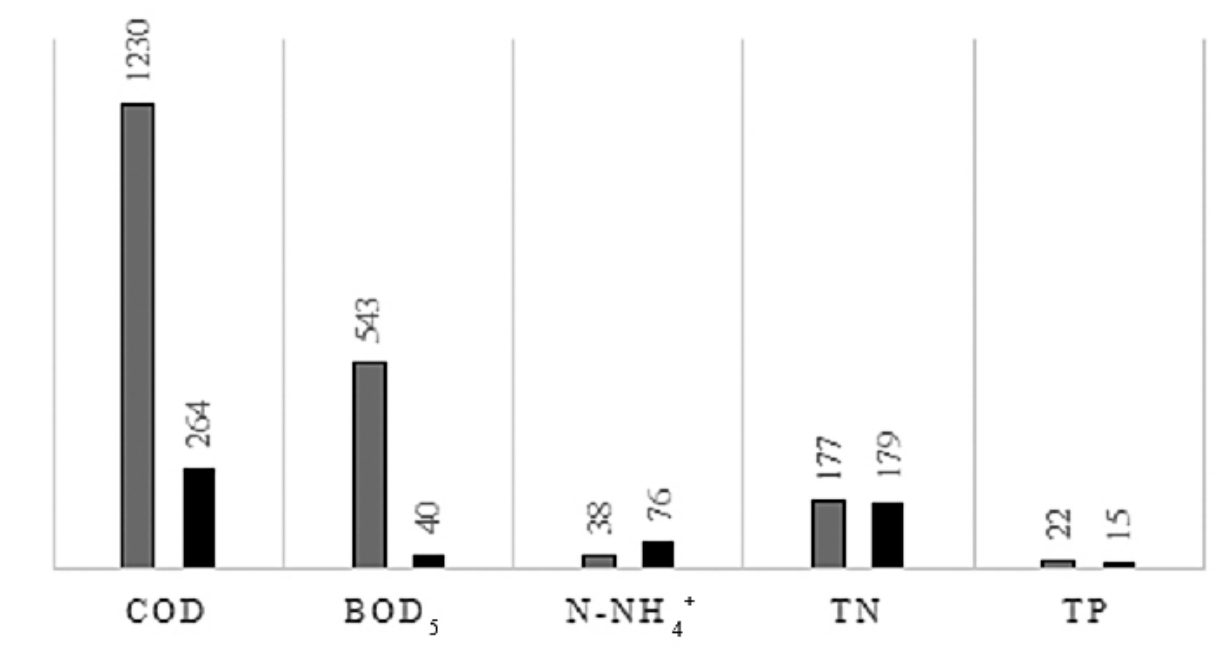

口Contaminations load in wastewater $[\mathrm{kg} / \mathrm{d}] \quad$ Contaminations load in reject water $[\mathrm{kd} / \mathrm{d}]$

Figure 3. Comparison of pollutants load in raw sewage and the reject water generated in ATAD process in WWTP

Table 2. The characteristics of reject water from ATAD process before and after treatment $(n=12)$ in SS VF bed and removed pollutants load

\begin{tabular}{|c|c|c|c|}
\hline Parameter & Inflow $\left(\mathrm{mg} \mathrm{l}^{-1}\right)$ & $\begin{array}{l}\text { Outflow } \\
\left(\mathrm{mg} \mathrm{l}^{-1}\right)\end{array}$ & $\begin{array}{c}\text { Removed load } \\
\left(\mathrm{g} \mathrm{m}^{-2} \mathrm{~d}^{-1}\right)\end{array}$ \\
\hline $\mathrm{BOD}_{5}$ & $330 \pm 47$ & $48 \pm 6$ & $28.2 \pm 4.9$ \\
\hline COD & $2200 \pm 212$ & $1100 \pm 169$ & $110 \pm 17.0$ \\
\hline TOC & $711 \pm 82$ & $299 \pm 39$ & $41.2 \pm 6.8$ \\
\hline TKN & $1487 \pm 166$ & $619 \pm 72$ & $86.8 \pm 14.5$ \\
\hline $\mathrm{N}-\mathrm{NH}_{4}{ }^{+}$ & $636 \pm 76$ & $347 \pm 55$ & $28.9 \pm 3.9$ \\
\hline $\mathrm{N}-\mathrm{NO}_{3}^{-}$ & $4.0 \pm 0.8$ & $49.7 \pm 6.6$ & - \\
\hline $\mathrm{N}-\mathrm{NO}_{2}^{-}$ & $0.6 \pm 0.1$ & $0.1 \pm 0.02$ & - \\
\hline TP & $128.5 \pm 16.7$ & $86.3 \pm 7.0$ & $4.2 \pm 1.1$ \\
\hline
\end{tabular}

Mean \pm Standard deviation

phosphorus from 217 to $327 \mathrm{mg} \mathrm{P}^{-1}$. The results of his research, conducted with stabilization time of 4,6 and 8 days, point to the conclusion that the ammonia nitrogen and total nitrogen concentrations in the reject water decrease when the sludge stabilization time is extended. In increased temperature and high $\mathrm{pH}$, ammonia nitrogen occurs as ammonia and is released into the atmosphere. Ammonia nitrogen cannot undergo biological oxidation into nitrite and nitrate as nitrification does not occur during the ATAD process. Moreover, the research carried out by the same author showed that the increased concentration of phosphorus compounds in reject water was not as great as in the case of nitrogen. Extension of the stabilization time caused an increased release of phosphorus from sludge, but it also supported phosphorus assimilation and storage by thermophilic microorganisms. Transferring great amounts of nitrogen and phosphorus to reject water during the ATAD process must be taken into consideration while designing such installations in WWTPs.

The concentration of pollutants in the reject water generated during the ATAD process is similar to the one observed in the reject water from the dewatering of sludge after the digestion process. The ammonia nitrogen concentration, which is of great importance in this research, is similar to the one reported by other authors. According to Hans \& van der Roest [1997], it reaches $657 \pm 56$ $\mathrm{mg} \mathrm{N}-\mathrm{NH}_{4}^{+} \mathrm{l}^{-1}$ and according to Fux et al. [2003] it

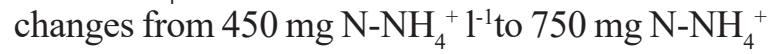
$\mathrm{1}^{-1}$. On the other hand, according to Sperczyńska [2016], the average pollutants concentrations are: ammonia nitrogen $844 \mathrm{mg} \mathrm{N}-\mathrm{NH}_{4}^{+}{ }^{-1}$, TKN 891

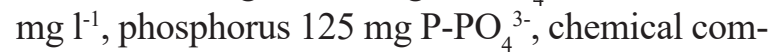
pounds expressed as ChZT $592 \mathrm{mg} \mathrm{O}_{2}{ }^{1-1}$.

The low value of $\mathrm{BOD}_{5} / \mathrm{COD}$ points to low biodegradability of the reject water from the ATAD process. It is lower than in the case of the reject water from the aerobic sewage sludge stabilization in dairy WWTPs, which ranged from 0.35 to 0.66 [Dąbrowski et al. 2017]. What is more, it is also lower than in the case of the reject water from the anaerobic sludge stabilization in municipal WWTPs, which - according to various authors - varied from 0.2 to 0.54 [Fux et al. 2006, Gajewska \& Obarska - Pempkowiak 2013]. According to Klimiuk et al. [2007], the $\mathrm{BOD}_{5} / \mathrm{COD}$ and $\mathrm{BOD}_{5} / \mathrm{TN}$ ratios decrease in progress with the decomposition process. Their low values point to the lack of necessity of high efficiency treatment with the activated sludge system or a trickling fil- 
ter. Moreover, the content of easily biodegradable organics is insufficient; hence, the conventional path of nitrogen removal cannot be applied. New microbiological processes, such as SHARON, Anammox, or CANON can be used for nitrogen removal [Ryzińska 2006]. Constructed wetlands might also be applied for that purpose. According to data given by Kadlec \& Wallace [2009], the $\mathrm{BOD}_{5} / \mathrm{TKN}$ ratio value below 1 is necessary for ensuring effective nitrification process in constructed wetlands. Figure 4 presents the graphical interpretation of the statistical analysis of influent, effluent and removed loads.

The calculated treatment efficiency was on average at: $\mathrm{BOD}_{5} 85.1 \%$, COD $50.0 \%$, TOC $57.9 \%$,


Similar values were obtained in the case of treating the reject water from digested sludge dewatering [Gajewska \& Obarska-Pempkowiak 2013].

Generally, the effectiveness of removing organic compounds expressed as $\mathrm{BOD}_{5}$ is similar to that observed in the case of high concentration household sewage or septage under comparable climatic conditions. Slightly inferior results were obtained for COD, which is caused by lower biodegradability of reject water from the ATAD process $\left(\right.$ ratio $\left.\mathrm{BOD}_{5} / \mathrm{COD}=0.04\right)$. In the case of total and ammonia nitrogen, high treatment efficiency was observed mainly due to high concentration of nitrogen in the reject water. The phosphorus removal effect was more stable than in the case of household sewage and septage treatment [Karolinczak \& Dąbrowski 2017, Obarska-Pempkowiak et al. 2015].

The effectiveness of removing ammonia nitrogen in a CW bed of $45 \%$ is much lower than the effectiveness of its removal using advanced methods. In the SHARON method, ammonia nitrogen is removed with over the effectiveness of 90\% [van Kempen et al. 2001]. Taking into consideration a substantial cost of installation and high exploitation demand, its application is not justified in most facilities.

An alternative method of reject water treatment might be the one involving the chemical process of precipitation. The aim of the research conducted by Sperczyńska [2016] was to evaluate the effectiveness of removing phosphorus
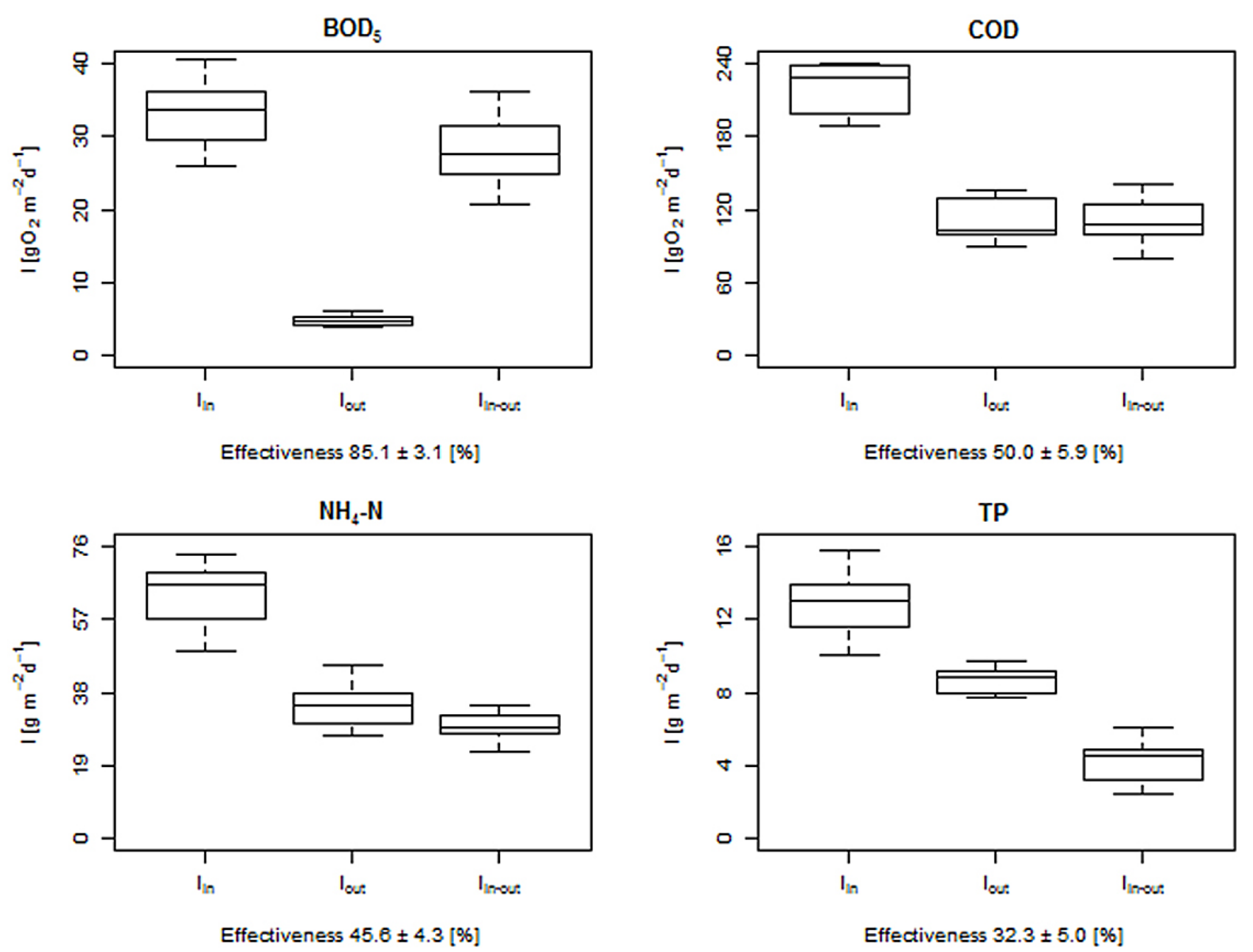

Figure 4. Graphical interpretation of the statistical analysis 
compounds from post-fermentation reject water using pre-hydrolyzed polialuminium chlorides and aluminium sulfate. The removal effectiveness changed from 51 to $96 \%$, while the removal effectiveness of organic compounds measured as COD increased from 19 to $47 \%$, depending on the kind and dose of coagulant. In the authors' own research, the average effectiveness of removing phosphorus in a CW bed was lower and reached $32 \%$, while the effectiveness of removing organic compounds and some non-organic elements measured as COD was higher.

The problem of minimizing the negative impact of reject water requires applying economically justified methods. They should be a compromise between highly effective and cost biological methods and a total omission of the reject water pre-treatment process.

\section{CONCLUSIONS}

The ATAD technology is commonly used in municipal and industrial WWTPs with PE less than 30.000. In such an object, applying anaerobic sewage sludge stabilization is not justified. The main problem related to the ATAD exploitation is a high concentration of nitrogen and phosphorus in the reject water from sewage sludge treatment and air purification (odor removal). The issue concerns mainly the highly loaded systems operating with SBRs without averaging tanks.

In the conducted research it was proven that applying separate reject water treatment with SS VF beds might ensure stable and effective functioning of municipal WWTPs by decreasing the load of biological part of WWTP. The efficiency of reject water treatment during the research period was on average $45.6 \%$ for ammonia nitrogen, $32.3 \%$ for total phosphorus and $85.1 \%$ for BOD $_{5}$. An innovative type of filling was used in SS VF beds, which was produced from waste (ash from a heat and power plant). Its application decreases the negative impact on the environment connected with exploitation of extracted aggregate (sand and gravel) and decreases the amount of waste.

\section{Acknowledgements}

The study was conducted as a research project S/WBiIŚ/3/2014 in Faculty of Building and Environmental Engineering of BUT and financed by Ministry of Science and Higher Education of Poland.

\section{REFERENCES}

1. American Public Health Association (APHA) 2005.Standard Methods for Examination of Water and Wastewater. 21st edition. American Public Health Association, Washington.

2. Bartkowska I., Dzienis L. 2007. Technical and economic aspects of autothermal thermophilic aerobic digestion exemplified by sewage treatment plant in Giżycko. Env. Prot. Eng. 33(2), 17-24.

3. Bartkowska I. 2016. Alternative application of ATAD process for sewage sludge stabilization, Gaz Woda i Technika Sanitarna, 90(11), 413-417, doi: 10.15199/17.2016.11.4 (in Polish)

4. Bartkowska I. 2017. Autothermal Thermohilic Aerobic Digestion. Seidel-Przywecki, Warsaw, (in Polish).

5. Borowski S. 2000. Aerobic thermophilic sewage sludge stabilization, Ochrona Środowiska 4(79), 21-25 (in Polish).

6. Carvalho P.N. , Arias A.C., Brix H. 2017. Constructed Wetlands for Water Treatment: New Developments. Water 9, 397, doi: 10.3390/w9060397.

7. Dąbrowski W., Karolinczak B., Gajewska M., Wojciechowska E. 2017. Application of subsurface vertical flow constructed wetlands to reject water treatment in dairy wastewater treatment plant. Environmental Technology 38(2), 175-182. http:// doi.org/10.1080/09593330.2016.1262459.

8. Dąbrowski W. 2014. A study of the digestion process of sewage sludge from dairy WWTP to determine the composition and load of reject water, Water Pract. Technol. 9(1), 71-78.

9. Fux Ch., Valten S., Carozzi V., Solley D., Keller J. 2006. Efficient and stable nitrification and denitrification of ammonium-rich sludge dewatering liquor using SBR with continuous loading, Water Research 40 (14), 2765-2775.

10. Gajewska M., Obarska-Pempkowiak H. 2013. Multistage treatment wetland for treatment of reject waters from digested sludge dewatering, Water Sci. Technol., 68(6), 1223-1232.

11. Guo C.H., Kuang S.L., Stabnikov V., Ivanov V. 2009. The removal of phosphorus from wastewater using anoxic reduction of iron ore in the rotating reactor. Biochem. Eng. J. 46, 223-226.

12. Janus H.M., van der Roest H.F. 1997. Do not reject the idea of treating reject water, Water Sci. Technol. 35(10), 27-34.

13. Kadlec, R.H, Wallace S.D., 2009. Treatment Wetlands, 2nd ed.; CRC Press: Boca Raton, FL, USA.

14. Karolinczak B., Dąbrowski W. 2017. Effectiveness of septage pre-treatment in vertical flow constructed wetland. Water Science and Technology, 76.9, 2544-2553, doi: 10.2166/wst.2017.398. 
15. Kempen R., Mulder J.W., Uijetrlinde C.A., Loosdrecht M.C.M. 2001. Overview: full scale experience of the SHARON process for treatment rejection water of digested sludge dewatering, Water Science and Technology 44(1), 145-152.

16. Klimiuk E., Kulikowska D., Koc-Jurczyk J. 2007. Biological removal of organics and nitrogen from landfill leachates - a review. In: Management of Pollutant Emission from Landfills and Sludge (M. Pawłowska \& L. Pawłowski, eds.), Taylor and Francis Group, London, 187-204.

17. Liang Y., Zhu H., Bañuelos G., Yan B., Zhou Q., Yu X., Cheng X. 2017. Constructed wetlands for saline wastewater treatment: A review, Ecological Engineering, 98, 275-285.

18. Layden N.M., Mavinic D.S., Kelly H.G, Moles R., Bartlett J. 2007.Autothermal thermophilic aerobic digestion (ATAD) - Part I: Review of origins, design, and process operation, Journal of Environmental Engineering and Science, 6(6), 665-678, https://doi.org/10.1139/S07-015

19. Meyer S.S., Wilderer A., 2004. Reject Water: Treating of Process Water in Large Wastewater Treatment Plants in Germany - A Case study, Journal of Environmental Science and Health, 39(7), 1645-1654.

20. Obarska - Pempkowiak H., Gajewska M., Wojciechowska E., Kołecka K. 2015. Sewage gardens - constructed wetlands for single family households, Environmental Protection Engineer- ing, 41(4), doi: 10.5277/epe150406.

21. Regulations of the Minister of Environment from 18th of November 2014 on conditions to be met for disposal of treated sewage into water and soil and concerning substances harmful to the environment (Dz.U. 2014. no. 1800) (in Polish)

22. Rosenwinkel K.H., Beier M., Phan L. C., Hartwig P. 2009. Conventional and advanced Technologies for biological nitrogen removal in Europe, Water Practice \& Technology, 4(1), doi: 10.2166/ WTP.2009.014

23. Ryzińska J. 2006. Problems of reject water and possibility of its treatment in Poland, Gaz, Woda i Technika Sanitarna, 7-8, 58-62 (in Polish).

24. Shugen L., Nanwen Z., Loretta Y.L. 2011. The one-stage autothermal thermophilic aerobic digestion for sewage sludge treatment, Chemical Engineering Journal, 174 (2-3), 564-570, https://doi. org/10.1016/j.cej.2011.09.043

25. Sperczyńska E.2016.Usuwanie fosforanów $z$ pofermentacyjnych cieczy osadowych. Ecological Engineering 46, 196-201, doi: 10.12912/23920629/63262, (in Polish).

26. Tan Y.Y., Tang F. E., Ho C.L.I., Jong V.S.W. 2017. Dewatering and treatment of septage using vertical flow constructed wetlands, Technologies 5(70), doi: 10.3390/technologies5040070

27. Website of LSA sp. z o.o. http://lsa.biz.pl/ 